\title{
Study of Mass in Right Iliac Fossa
}

\author{
Dr.M.V.Naveen Reddy ${ }^{1}$,Dr.M.Rupa Reddy ${ }^{2 *}$ \\ ${ }^{1}$ Associate Professor, Department Of General Surgery, Shadan Institute Of Medical Sciences, Hyderabad, \\ Telangana, India. \\ ${ }^{2}$ Associate Professor, Department Of Obstetrics \& Gynaecology, Shadan Institute Of Medical Sciences, \\ Hyderabad,Telangana, India.
}

\begin{abstract}
Mass in right iliac fossa is one of the most common condition seen in surgical practice which has various differential diagnosis with most of them being curable. The objective of the study is to identify various diseases which can present with mass in right iliac fossa. This is a study conducted on patients having mass in right iliac fossa admitted in Shadan hospital over a period of two years. 60 patients(30 male and 30 female) with the provisional diagnosis of right iliac fossa mass was included in the inclusion criteria and patients with masses arising from parietal wall, children below 10 years of age, pregnancy and any bony swelling in the region were excluded after radiological assessment. Most of the right iliac fossa masses seen were of appendicular pathology followed by ileocaecal tuberculosis. $70 \%$ of the cases were related to appendicular pathology either appendicular mass or abscess, ileocaecal tuberculosis $16.6 \%$ and amoebic typhlitis the least .
\end{abstract}

Keywords: Mass in right iliac fossa , Appendicular mass, Ileocaecal tuberculosis, Carcinoma Caecum, Appendicectomy, Hemicolectomy, Right ovarian cyst.

\section{Introduction}

Mass in right iliac fossa is of one of the commonest entity seen in surgical practice with diverse differential diagnosis. Mass may develop either in the structures normally present in right iliac fossa or may originate from organs lying in other region and abnormally invade this region .Most common being appendicular lump either mass or abscess. The main purpose of the study is to know the incidences of each differential diagnosis of mass in right iliac fossa. Most of the cases need surgical intervention but some are managed conservatively and most of them are curable. The structures which are normally present in this region are: 1)Appendix 2) Caecum 3) Terminal part of the ileum 4) lymph nodes 5) Iliac arteries 6) Retroperitoneal connective tissue 7)Iliopsoas sheath 8)Ilium. Structures which are lying in other regions and which may invade right iliac region are i)Undescended kidney ii) Gall bladder iii) Uterine swelling iv)Urinary vesical swelling v) Undescended testes vi) Pelvic abscess vii)Ovarian cyst. Important differential diagnosis is between appendicular mass, abscess, carcinoma caecum and intestinal tuberculosis. Intestinal tuberculosis is seen more commonly in people of poor socioeconomic status. There will be early involvement of regional lymph nodes which become matted along with involved terminal part of ileum and caecum to produce the lump. Caecal carcinoma is more common in high socio-economic people who use less fibrous[5] and purified diet. Carcinoma of caecum[1] is curable when diagnosed early and treated.

Diagnosis of abdominal mass mainly depends on clinical examination and investigations. The main intention of this study is to know the incidence, varying modes of presentation, different modalities of diagnosis, treatment and prognosis in our set up and to identify factors which can help in better management of these cases thus helping to improve the prognosis and management care. Right iliac fossa: It is bounded anteriorly by skin, subcutaneous tissue, external oblique aponeurosis, internal oblique aponeurosis, transverse abdominis and posteriorly it is bounded by psoas muscle, quadratus lumborum muscle and thoracolumbar fascia. Inferiorly it is bounded by posterior part of ilium and iliacus muscle. Laterally bounded by external oblique, internal oblique, transverse abdominis and transversalis fascia.

Appendix: Embryologically, the appendix and caecum develops as outpouchings of the caudal limb of the midgut loop in the sixth week of human development. By the fifth month, the appendix elongates into its vermiform shape. At birth, the appendix is located at the tip of the caecum , the adult appendix typically originates from the posteromedial wall of the caecum, caudal to ileocaecal valve. Missing tumours or other diagnosis of mass in right iliac fossa could be carcinoid tumour of appendix with incidence of 3 to 7 in every 1000 appendectomies. Appendicitis associated with colon cancer was $0.85 \%$ and the time from appendectomy to the recognition of colon carcinoma was a median delay of 5 to 8 months. High index of suspicion for elderly patients presenting with anaemia and right iliac fossa pain / mass should have careful diagnostic investigations including CT scan / colonoscopy. 


\section{Methodology}

The study was conducted on patients with mass in the right iliac fossa admitted in Shadan Hospital between September 2013 and November 2015. All patients who presented with mass in right iliac fossa underwent detailed clinical examination with relevant investigations[16] for the definitive management. This is a descriptive type of study.Of the total 60 patients studied, 30 were male and 30 were female patients.

All patients who came with complaints of mass in right iliac fossa and in right lower part of abdomen underwent a detailed clinical examination. All patients with mass in right iliac fossa then underwent the relevant investigations[2] following the routine blood and urine investigations like CBP, Blood grouping and $\mathrm{Rh}$ typing ,ESR, HIV, HBsAg ,RBS ,CUE. Ultrasonography[10] was done in all patients. Subsequently chest x-ray, CTscan[15] , IVP ,Ca 125 levels, colonoscopy and barium follow through and enema were done as and when required. After the necessary investigations and after arriving at a final diagnosis, appropriate treatment was given either conservatively or by surgery. The patients were monitored closely post operatively for any complications. Patients were advised to come for follow up.

Patients with masses arising from parietal wall, children below 10 years of age, pregnancy and any bony swelling in the region were excluded from the study.

\section{Objectives Of The Study}

1. To study the incidence of various diseases which can present with mass in the right iliac fossa in male and female patients .

2. To study age and sex distribution of conditions presenting with mass in right iliac fossa.

3. To identify most common condition presenting with mass in right iliac fossa.

4. To study the various modes of investigations available and management of various types of mass in right iliac fossa.

\section{Results And Discussion}

Table 1: Age Incidence

\begin{tabular}{|l|l|l|l|l|l|l|}
\hline Diagnosis & No.of cases & $11-20$ & $21-30$ & $31-40$ & $41-50$ & $51-60$ \\
\hline Appendicular mass & 27 & 4 & 12 & 9 & 2 & - \\
\hline $\begin{array}{l}\text { Appendicular } \\
\text { abscess }\end{array}$ & 15 & 3 & 5 & 4 & 3 & - \\
\hline $\begin{array}{l}\text { Ileocaecal } \\
\text { tuberculosis }\end{array}$ & 10 & 2 & 5 & 2 & 1 & - \\
\hline Ca. Caecum & 3 & - & - & - & - & 3 \\
\hline $\begin{array}{l}\text { Right Tubo-ovarian } \\
\text { mass }\end{array}$ & 2 & - & 2 & - & - & - \\
\hline Right Ovarian cyst & 2 & - & 1 & 1 & - & - \\
\hline $\begin{array}{l}\text { Amoebic } \\
\text { Typhlitis }\end{array}$ & 1 & - & - & 1 & - & - \\
\hline Total & 60 & 9 & 25 & 17 & 6 & 3 \\
\hline
\end{tabular}

In our study, it was observed that the youngest patient was of age 16 years who presented with appendicular mass and the oldest was 59 years of age admitted with carcinoma of caecum. Appendicular mass was seen more commonly in $3^{\text {rd }}$ and $4^{\text {th }}$ decade followed by $2^{\text {nd }}$ decade. Appendicular abscess was common in $3^{\text {rd }}$ decade. Ileocaecal tuberculosis[14] was common in $3^{\text {rd }}$ and $4^{\text {th }}$ decade. Carcinoma caecum was common in $6^{\text {th }}$ decade.

Table 2: Incidence Of Various Conditions

\begin{tabular}{|c|c|c|}
\hline Diagnosis & $\begin{array}{c}\text { No. of cases } \\
(60)\end{array}$ & Percentage \\
\hline Appendicular mass & 27 & $45 \%$ \\
\hline Appendicular abscess & 15 & $25 \%$ \\
\hline Ileocaecal tuberculosis & 10 & $16.6 \%$ \\
\hline Ca caecum & 3 & $5 \%$ \\
\hline Right Tubo-ovarian mass & 2 & $3.3 \%$ \\
\hline Right Ovarian cyst & 2 & $3.3 \%$ \\
\hline Amoebic Typhlitis & 1 & $1.6 \%$ \\
\hline Total & 60 & $100 \%$ \\
\hline
\end{tabular}

Majority of the cases had appendicular mass(45\%) followed by appendicular abscess(25\%),10 cases had ileocaecal tuberculosis, right TO mass and right ovarian cyst in 2 cases each. 
Table 3: Sex Incidence

\begin{tabular}{|l|l|l|l|l|}
\hline \multirow{2}{*}{ Diagnosis } & \multicolumn{2}{|c|}{ Male } & \multicolumn{2}{c|}{ Female } \\
\cline { 2 - 5 } & No & $\%$ & No & $\%$ \\
\hline Appendicular mass & 11 & 36.6 & 16 & 53.3 \\
\hline Appendicular abscess & 10 & 33.3 & 5 & 16.6 \\
\hline Ileocaecal tuberculosis & 6 & 20 & 4 & 13.3 \\
\hline Carcinoma Caecum & 2 & 6.6 & 1 & 3.3 \\
\hline Tubo-ovarian mass & - & - & 2 & 6.6 \\
\hline Ovarian cyst & - & - & 2 & 6.6 \\
& & & & \\
\hline Amoebic typhlitis & 1 & 3.3 & - & - \\
\hline Total & 30 & 100 & 30 & 100 \\
\hline
\end{tabular}

In our study, appendicular mass was predominantly seen in females. Appendicular abscess and ileocaecal tuberculosis was mostly seen males.

Most of the patients in the study presented with pain .Duration of pain was significantly more in appendicular mass and abscess .Loss of weight was significant in ileocaecal tuberculosis and ca.caecum . Fever ,vomiting ,dull aching abdominal pain were other presenting symptoms.

Mode of treatment: In our study, most of the patients required surgical intervention i.e, 14 cases were managed conservatively and remaining 46 cases required surgical intervention. Most of the cases with appendicular mass[6] were managed with O.S. regime followed by interval appendicectomy[4][7] 6 weeks later.

All cases of appendicular abscess, laparotomy with drainage of abscess[3] was done .In ileocaecal tuberculosis , 8 required ATT regimen with regular follow-up and in 2 cases right hemicolectomy[9] was done for intestinal obstruction. In $\mathrm{Ca}$. caecum all 3 patients were managed with radical right hemicolectomy with regular follow-up .In right tubo -ovarian mass 1 patient was treated conservatively with antibiotic therapy and other patient required laparotomy with salpingo-ophorectomy . 2 cases of right ovarian cyst required right ovarian cystectomy.

Table 4: Mode Of Treatment

\begin{tabular}{|l|l|l|l|}
\hline Diagnosis & \multicolumn{2}{|c|}{ No.of Cases } & \multicolumn{2}{|c|}{ Treatment } \\
\cline { 3 - 4 } & & Conservative & Surgical \\
\hline 1)Appendicular mass & 27 & 4 & 23 \\
\hline 2)Appendicular abscess & 15 & - & 15 \\
\hline 3)Ileocaecal tuberculosis & 10 & 8 & 2 \\
\hline 4)Ca Caecum & 3 & - & 3 \\
\hline 5)Tubo-ovarian mass & 2 & 1 & 1 \\
\hline 6)Ovarian cyst & 2 & - & 2 \\
\hline 7)Amoebic typhlitis & 1 & 1 & - \\
\hline
\end{tabular}

\section{Conclusion}

Appendicular pathology with incidence of $70 \%$ either in the form of appendicular mass or abscess was the commonest pathology seen in right iliac fossa region with age group between 20 to 40 years. The disease was more common in low socioeconomic group of people. Appendicular mass was more common in females but appendicular abscess and ileocaecal tuberculosis were predominant in males. Ultrasonography [13]remained to be the first choice of investigation. Only 14 cases required conservative treatment while 46 cases required surgical intervention. In patients with appendicular mass, initial conservative management with Oschner Sherrin's regime was done followed by interval appendicectomy[8][11]. Patients with appendicular abscess[12] underwent immediate appendicectomy and the complications were less .Cases of ileocaecal tuberculosis received ATT for 6 months .Surgery was main stay of treatment for carcinoma caecum .Laparotomy was done for cases of right ovarian cyst and cystectomy was done.

\section{References}

[1]. Amin MA, khan MA, Ayub M, Mahmood M, Ashraf M, Choudhry AR. Delay in diagnosis and prognosis of caecal carcinoma- A study of 20 cases. J Ayub Med coll Abbotabad. Apr-Jan 2001; 13(2):28-31.

[2]. Gladman MA, Knowler CH, Gladman LJ et al. Intraoperative culture in appendicitis. Traditional practice challenged. Ann R Coll Surg Engl 2004;86:196-201.

[3]. Brown CV, Abrishami M, Muller M et al.Appendiceal abscess: Immediate operation or percutaneous drainage? Am Surg $2003 ; 69: 829-832$.

[4]. Vane DW, Fernandez N. Role of interval appendicectomy in the management of complicated appendicitis in children. World J Surg 2006;30:51-54.

[5]. Michels KB, Edward G, Joshipura KJ et al. Prospective study of fruit and vegetable consumption and incidence of colon and rectal cancers. J Natt Cancer Inst 2000; $92: 1740-1752$.

[6]. Arshad M, Aziz LA, Qasim M, Talpur KA. Early appendicectomy in appendicular mass - a Liaquat University Hospital experience. J Ayub Med Coll Abottabad. 2008 Jan-Mar;20 (1):70-2. 
[7]. De-U, Ghosh S. Acute appendicectomy for appendicular mass. A study of 87 patients. Ceylon Med J Dec2002;47(4):117-8.

[8]. Adalla SA. Appendicular mass. Interval appendicectomy should not be the rule. Br J Clin Pract, Apr-May 1996;50 (3):168-9.

[9]. Elhence IP, Sharma BD et al. Surgical treatment of abdominal tuberculosis. IJS, Jun-July 1984; 46(647):337-340.

[10]. Ripolles T, Martinez-Perez MJ, Morote I, Solaz J. Diseases that simulate acute appendicitis on ultrasound. Br J Radiol, Jan 1998; 71(841):94-8.

[11]. Gahukamble DB, Gahukamble LO. Surgical and pathological basis for interval appendicectomy after resolution of appendicular mass in children. J Pediatr Surg, Mar 2000; 35(3):424-7.

[12]. Hurme T, Nylamo E. Conservative versus operative treatment of appendicular abscess. Ann Chir Gynaecol 1995;84(1):33-6.

[13]. Malik A, Sazena NC. Ultrasound in abdominal tuberculosis. Abdom Imaging, July-Aug 2003;28(4):574-9.

[14]. Byron HB, Mamn CV. Clinical features and surgical management of ileocaecal tuberculosis. Proc R Soc Med, 1969 Dec; 62(12):1230-33.

[15]. Yilmaz T et al. CT findings of abdominal tuberculosis in 12 patients. Comput Med Imaging Graph , Sept-Oct 2002;26(5):321-5.

[16]. Afzal S, Qayum I, Ahmed I, Kundi S. Clinical diagnostic criteria for suspected ileocaecal tuberculosis. J Ayub Med Coll Abbottabad 2006 Oct-Dec; 18(4):42-6. 